\title{
Planejamento e burocracia na prática escolar: sentidos que assumem na escola pública
}

\author{
Planning and bureaucracy in school practice: Senses that take in public \\ schools \\ Planificación y burocracia en la práctica escolar: sentidos que asumen en la \\ escuela pública
}

MIGUEL HENRIQUE RUSSO

Resumo: A partir de relato extraído de uma pesquisa empírica e de alguns pressupostos sobre a prática do planejamento no âmbito escolar, o texto desenvolve reflexão crítica com vistas a melhor compreensão dos determinantes imediatos daquele processo numa escola pública. $\mathrm{O}$ relato da pesquisa revela uma prática repetitiva e espontânea. A leitura do texto pode avivar a experiência vicária e orientar a prática escolar segundo uma perspectiva na qual o planejamento seja um instrumento metodológico de construção do projeto escolar e assuma, assim, um papel de catalisador da reflexão coletiva na escola.

Palavras-chave: Planejamento escolar; prática escolar; plano escolar.

\begin{abstract}
This article relies on a report from an empirical research to discuss the practice of school planning. Given that the report reveals repetitive and spontaneous practices, the paper proposes a critical reflection to better understand the internal factors of administrative planning that take place in a public school. The text seeks to highlight vicarious experiences and guide school practices with a perspective in which school planning is a methodological tool for building a school project that stimulates collective reflections.
\end{abstract}

Keywords: School planning; school practices; school plan.

Resumen: A partir del informe de una investigación empírica y algunas suposiciones básicas acerca de la práctica de la planificación en ámbito escolar, el texto desarrolla una reflexión crítica con el fin de comprender mejor los determinantes inmediatos de aquel proceso en una escuela pública. El informe de la investigación revela una práctica repetitiva y espontánea. La lectura del texto puede inspirar experiencias indirectas y guiar la práctica escolar de acuerdo con una perspectiva en la que la planificación sea una herramienta metodológica para la construcción del proyecto escolar y asuma, así, un papel de filtro de la reflexión colectiva en la escuela.

Palabras clave: Planificación escolar; práctica escolar; plan de la escuela. 


\section{INTRODUÇÃO}

A tendência cíclica, no campo da educação, de pôr ênfase em algumas abordagens e em determinados temas tem, em relação ao planejamento, um capítulo especial. No Brasil, ele já foi o cerne das políticas e das práticas educacionais nas décadas de 1960 e 1970. No plano da macro política muitos Planos de Educação se sucederam como instrumento de gestão governamental. Igualmente, no plano da prática escolar ocorreu o predomínio de metodologias que enfatizavam o planejamento como mecanismo introdutório de certa racionalidade no campo educação. O tecnicismo daquele período se assentou no comportamentalismo skineriano para o qual ter clareza das finalidades da educação importava planejar detalhadamente o processo ensino-aprendizagem, operacionalizando seus objetivos educacionais e instrucionais. O planejamento era, assim, considerado ponto de partida para a fixação dos conteúdos correspondentes a serem desenvolvidos em cada área ou disciplina, bem como para a opção pela melhor estratégia didática a ser utilizada no ensino. Naquele período, a avaliação era importante somente como mecanismo de retroalimentação (feedback) para um eventual replanejamento.

Com a redemocratização, perdeu força o tecnicismo, que foi logo substituído pelas políticas neoliberais, que se impõem no campo da educação. Nestas, em face da importância estratégica que têm para a consolidação do modelo político-social e econômico, a ênfase é na avaliação. Residem aí as causas da elevação das práticas avaliativas ao ponto mais alto dos estudos e práticas educacionais, isto é, a avaliação ganha nova importância como mecanismo indutor de mudanças com vistas à redução dos gastos públicos com as políticas sociais em geral e com as educacionais em particular.

A reflexão realizada neste texto tem como foco o planejamento no âmbito escolar. Inicialmente, realizo uma incursão no campo do planejamento com vistas a sua conceituação e à discussão de aspectos de sua execução na escola. Para tanto, utilizo parcialmente um texto que preparei, ainda na década de $1990^{1}$, para orientar o planejamento das unidades escolares de uma rede pública. Em seguida, a partir do registro parcial de uma pesquisa que realizei, também naquela década, apresento a descrição de observações feitas durante a realização do planejamento na escola pesquisada ${ }^{2}$. Mesmo decorridos vários anos e tendo ocorrido mudanças na legislação educacional, ambos os documentos se mantêm atualizados em face

\footnotetext{
1 Texto elaborado para orientar o processo de planejamento nas Escolas Técnicas da rede do Centro Estadual de Educação Tecnológica "Paula Souza” (CEETPS), no ano de 1991.

2 Relato da observação empírica, item 3.5.3 - Cena 3 - “O planejamento e o projeto escolar"- da tese de doutorado do autor (RUSSO, 1995)
}

194 - RBPAE - v. 32, n. 1, p. 193 - 210 jan./abr. 2016 
da constatação de que a realidade do cotidiano escolar pouco se alterou no que tange à temática do planejamento. Ao final, registro algumas considerações sobre o apresentado.

\section{PLANEJAMENTO}

Planejar é antecipar o futuro no sentido de prever ações a serem desenvolvidas para se conseguir objetivos determinados. As ações ocorrem sempre em determinado contexto cujos parâmetros e contornos podem ser estimados com maior ou menor precisão. Por isso, o planejamento inicial não consegue dar conta de prever as condições reais em que se dará a ação, exigindo, assim, correções sucessivas com a aproximação desta.

No caso do planejamento escolar, o período inicial de planejamento é só um primeiro momento de organização da ação coletiva, que exigirá novos momentos de reflexão e ajustes (replanejamento).

O planejamento é um processo, portanto dinâmico, que não se confunde com seu produto sob a forma escrita, isto é, o plano. O principal produto do planejamento é imaterial e consiste na melhoria das condições individuais, e de grupo, para o desenvolvimento de um trabalho coletivo que exige integração de ações para garantir o alcance de objetivos estabelecidos.

Quando o planejamento é encarado como instrumento de controle burocrático, como em geral acontece, sua avaliação recai sobre o produto, isto é, no plano como documento. A riqueza do processo de planejamento está exatamente na oportunidade que ele cria para se proceder a uma revisão de todos os pressupostos e práticas até então adotadas.

Outro desvio provocado pela visão burocrática é a exagerada ênfase nos aspectos formais da elaboração dos planos. Sem diminuir a importância e necessidade da adequada formulação do plano, há que se dar-lhe um valor relativo, que não comprometa a qualidade da participação política dos elaboradores.

O planejamento educacional em todas as suas modalidades (curricular, de escola, de ensino, etc.) é um ato político-pedagógico que exige a participação do coletivo dos educadores da escola. Ingenuamente os educadores têm entendido e procedido como se o planejamento fosse uma técnica organizatória política e ideologicamente neutra. Isto tem, em parte, explicado a pouca importância dada ao planejamento, e até a omissão de significativa parcela dos professores para com ele.

Ao contrário dessa perspectiva, o planejamento deveria ser visto como instrumento de luta dos professores contra o domínio da tecnocracia que se impõe ao processo educativo. Basta, para isso, que se empenhem em participar 
ativamente, comprometendo-se com os interesses dos alunos, de um ensino de qualidade, priorizando as questões pedagógicas substantivas e relevantes para a melhoria das condições de ensino e aprendizagem, que constituem o espaço de luta que a escola tem para contribuir com a transformação da sociedade burguesa. A consecução do projeto escolar e a execução do currículo envolve a participação de todos os professores e especialistas da escola. É imprescindível, portanto, que o planejamento seja um ato coletivo de todos aqueles educadores, que, juntos, irão decidir que escola irão oferecer aos seus alunos.

As condições do contexto escolar e da clientela não devem impor-se como fontes de um determinismo que sela as possibilidades de atuação da escola. Pelo contrário, as eventuais carências materiais, financeiras e humanas têm que ser superadas pela força da criatividade e da solidariedade coletivas. Há que se eliminar os voluntarismos idealistas e individualistas, pela organização coletiva consciente que agregue experiências e produza novas sínteses na percepção sobre educação e escola, que possam representar avanços para cada um dos membros.

Planejar implica a identificação e explicitação das metas coletivamente eleitas. Essa é, talvez, uma das mais delicadas e sensíveis etapas do planejamento. Ela pressupõe razoável conhecimento das condições concretas existentes na escola, como ponto departida; a esclarecida clareza das questões sociais envolvidas no trabalho da escola e suas competências para implementá-los, no estabelecimento de metas, como ponto de chegada. São essas metas que irão balizar o trabalho de cada um e não o contrário, como geralmente ocorre. As decisões sobre a direção que se dará à escola enquanto instituição social antecedem e se sobrepõem àquelas que cada um tomará para orientar seu trabalho. Isso significa e reforça a necessidade de uma abertura para a participação democrática de todos os educadores no planejamento da escola.

É também pela participação coletiva que se irá selecionar, dentre as metas eleitas, aquelas fundamentais e as que são acessórias. Com esta etapa se estarão estabelecendo aquelas ações que merecerão a atenção de todos os membros da equipe de educadores e o tratamento adequado delas face aos objetivos da educação e da escola.

Não parece necessária longa argumentação para enfatizar a importância do planejamento em qualquer empreendimento humano e na educação em particular. No caso da escola, vista como organização complexa e específica, mais do que na maioria das outras organizações, o planejamento exige um tratamento democrático e participativo. Cabe, entretanto, ao grupo gestor da escola o decisivo papel de estimular e garantir as condições favoráveis a que esse processo se efetive com razoável eficácia e eficiência. 
Superar a visão burocrática que tem presidido o planejamento, transformando-o num momento de grande riqueza para a reflexão e apreensão da realidade em todas as suas múltiplas facetas é um dos desafios postos aos educadores.

Dentre as várias definições que exigem posição pessoal do diretor está a atenção que ele dará ao planejamento. Ela será uma sinalização sobre a dimensão do trabalho do diretor que será priorizada: a administrativa ou a pedagógica.

Há fortes evidências de que a maioria dos diretores tem relegado a dimensão pedagógica a plano secundário. Em geral, essa postura decorre de duas vertentes: a) as demandas de natureza administrativa que ocupam significativo tempo do trabalho do diretor; b) a falta de interesse e competência para conduzir as questões de natureza pedagógica da escola.

Um desafio de quem coordena o processo de planejamento na escola é conseguir de seus agentes um compromisso político com o processo de construção coletiva do projeto escolar, bem como uma visão global do trabalho em todas assuas dimensões. Em face das concepções tradicionais de organização do trabalho, os professores são levados a crer que sua atuação é restrita ao ensino e que este nada tem a ver com a administração da unidade escolar. É essa visão de separação que precisa ser superada.

Administração escolar não é uma técnica isenta. Compete a ela a tomada de decisões que, direta ou indiretamente, interferem na decisão (ou a definem) sobre qual será o nível dasrelações da escola com o meio social ou a orientação das práticas pedagógicas que ela desenvolve para dar conta do seu mister.

Assim, à proposta de um processo participativo de planejamento está implicitamente associada uma visão de gestão democrática da escola. Essa relação, implícita, não está sempre suficientemente consciente para todos os membros da escola, ou de outra forma, é preciso que esteja explicita para todos, dirigentes e professores.

Ao participar do planejamento, dando sua contribuição para a definição de metas e objetivos, sugerindo estratégias para operacionalizá-los, o professor está assumindo o relevante papel de cogestor, posto que tais decisões estão dentre as de maior importância na esfera político-pedagógica e administrativa da escola.

Para se conseguir uma atuação qualificada de todos os participantes, há que se dar-lhes as condições exigidas e necessárias. Os professores que atuam na Educação Básica se mostram muito desinformados sobre os pressupostos teóricos e conjunturais necessários a uma reflexão aprofundada sobre a escola e sua gestão, incluindo aí, é lógico, o planejamento. Em geral, suas preocupações e interesses são dirigidos, quando não restritos, ao âmbito de suas atividades diretas e aos temas de sua disciplina. 
O processo de planejamento precisa ser pensado. Ao coordenador do processo cabe assegurar que os participantes detenham as informações que são pré-requisitos para uma atuação consciente e produtiva. Uma condição central para a superação desse quadro é garantir o domínio de alguns fundamentos sobre a escola, tais como: legislação básica sobre ensino; normas regimentais; estrutura organizacional da escola, com atribuições e competências dos órgãos e seus responsáveis; objetivos institucionais permanentes e transitórios; dados sobre a história, realidade atual e diagnóstico da escola.

Uma consequência da visão burocrática e formalista com que tem sido tratado o planejamento é a limitação dos temas postos em discussão nesse processo. Assim, no caso do planejamento de ensino, institucionalizou-se um padrão de caráter tecnicista no qual aparecem os indefectíveis objetivos, conteúdos, estratégias e avaliação. Tudo ordenado segundo modelos que se imprimem como formulários aplicáveis a todas as disciplinas, independentemente da sua natureza e do tratamento metodológico adotado.

O planejamento escolar deve assumir o caráter de um fórum de discussão de todos os temas presentes no cotidiano da escola. Alguns desses temas são, em geral, considerados irrelevantes para merecer a atenção dos professores, posto que extrapolam o âmbito do espaço tradicionalmente tido como seu. A rigorosa separação de espaços reservados a cada segmento escolar é, aliás, uma decorrência da burocratização da escola e uma expressão da divisão do trabalho absorvida do modo de produção capitalista.

São, entretanto, as questões do cotidiano, que fogem aos formulários tecnicistas, que tocam diretamente os alunos naquilo que constitui a dimensão psicossocial da organização escolar. Não tem sentido a integração dos planejamentos se na execução não houver uniformidade de procedimentos que garantam unidade às ações pedagógicas da escola e de seus agentes.

É comum nas reflexões que se desenvolvem durante as fases do planejamento partir-se de situações idealizadas que pouco, ou nada, têm a ver com a realidade concreta em que se dará a ação planejada. Assim é com a imagem do adolescente extraída dos manuais de psicologia; com os métodos e técnicas de ensino e avaliação tiradas dos livros de didática; com as condições de apoio material, financeiro e administrativo; etc.

Essa situação, em termos do planejamento, significa um desvio no diagnóstico, que terá consequência nos resultados pretendidos. É importante, e fundamental, que se adote como ponto de partida uma análise das condições concretas da escola para que se tenha clareza das possibilidades reais de alcance dos objetivos, assim como das ações e apoio necessários para isso. 
É através da discussão das questões cotidianas e da prática concreta de todos os agentes do processo escolar que se poderá chegar à essência dos problemas relevantes a serem atacados pelo conjunto dos educadores da escola, e às transformações que representem avanços qualitativos.

Outra consequência do processo de idealização da realidade, a ser evitada no planejamento, é a natural tendência de negação das deficiências institucionais, estigmatizadas pelos padrões dominantes de julgamento da eficiência organizacional. A escola, como qualquer organização complexa, apresenta processos patológicos de maior ou menor gravidade. Sem dúvida, no caso das organizações escolares, a enfermidade mais grave é a burocratização das relações pessoais e das atividades pedagógicas em geral. Imersa no oceano burocrático estatal, a escola tem comprometidas muitas de suas funções sociais sem se dar conta dessa disfunção, posto que a burocratização se instala como coisa natural e profundamente entranhada na cultura organizacional da sociedade capitalista.

É imperioso que se reconheçam as deficiências para delas dar conta. A omissão, ou a negação, das deficiências, e ou conflitos, organizacionais não contribuem para a superação dos mesmos. Ao contrário, são agravantes comumente cometidos nas organizações escolares. É da natureza das organizações humanas a existência de deficiências. Assim, não existe escola perfeita. Se houver, há que se mirá-la com suspeita.

Uma comum e grave incorreção praticada na elaboração de planos escolares, e de ensino, é a previsão de atividades que nunca ocorrerão porque não há condições objetivas para isso. A visão burocrática e a repetição que ela provoca nos planejamentos são algumas de suas causas. Outra é a ingenuidade política de professores que acreditam poder superar óbices irremovíveis para sua prática pedagógica. Uma terceira origem é de ordem psicossocial e está associada às representações que fazem os educadores da educação, a escola e seu próprio papel social.

Sobre essa última, é demasiado conhecido que o homem cria imagens e relações simbólicas que se estabelecem a partir de suas experiências, que são histórica e socialmente determinadas. Assim, além da experiência concreta adquirida através das ações práticas em contato com a realidade empírica, os indivíduos, consciente ou inconscientemente, produzem no imaginário um conjunto de explicações para essa realidade.

Fruto exclusivo de percepções e sensações abstratas, essas explicações, não encontrando justificativas no real, passam a constituir um nível de representações que orienta o comportamento dos indivíduos. Em outros termos: existem para o indivíduo níveis de realidade. O real (empírico) onde se dão as ações práticas, 
e o imaginário (simbólico) onde se encontram as explicações que o indivíduo produziu para o real (empírico), isto é, o que ele pensa que é o real.

A fala (discurso) do indivíduo é fortemente influenciada por seu imaginário. Há, portanto, que se lhe analise a fala e a contextualize, comparando-a com sua prática, posto que entre ambos pode haver divergências reveladoras de uma dicotomização entre real e imaginário. É importante a distinção entre ambos. Em geral, todos os indivíduos transitam entre o real e o imaginário. A consequência mais importante dessa distinção, para o nosso tema, é a clarificação de que o discurso não muda a realidade, ou melhor, a aparência da realidade.

Portanto, muitas vezes, ao se elaborar um planejamento, põe-se a funcionar nosso imaginário, que nos leva a prever atividades que não têm suporte objetivo para se realizar. É o discurso descolado da realidade. Esta última não reage ao primeiro e o planejado assume, então, seu lado ficcional.

Finalmente, aproveitando o tema deste item, carece que os educadores reflitam com profundidade e persistência sobre a coerência entre seu discurso e sua prática, sobre as consequências de um exacerbado imaginário que nos faz idealizar fantásticos resultados para uma prática condicionada à tão carente realidade socioeconômica e educacional brasileira.

\section{A PRÁTICA DO PLANEJAMENTO NA ESCOLA}

A partir do relato da observação do processo de planejamento realizado em uma escola pública pertencente à rede estadual de São Paulo, o texto discute o papel do planejamento escolar: enquanto instrumento metodológico de construção do projeto escolar, que privilegia mais o aspecto processual do que o produto; enquanto espaço privilegiado de participação dos professores na escola; e como expressão da autonomia da escola na fixação das suas finalidades, em relação ao aparelho burocrático de Estado.

O texto utiliza como fonte para o relato da observação empírica o item 3.5.3 - Cena 3 - O planejamento e o projeto escolar - da tese de doutorado do autor (RUSSO, 1995), que analisa a prática gestionária no cotidiano escolar a partir de um referencial teórico progressista (PARO, 1986).

A descrição do empírico revela uma prática burocratizada na qual o planejamento é visto como o cumprimento de uma exigência da legislação e das instâncias superiores da hierarquia do Estado. Com isso, como se poderá constatar no relato, privilegia-se o produto, isto é, o plano e o cumprimento dos prazos estabelecidos por instância da hierarquia da Secretaria da Educação para sua conclusão. Em decorrência, esvazia-se o planejamento daquilo que ele tem de mais relevante, e que decorre de sua natureza processual, que é oferecer a 
todos os agentes da escola o espaço para: uma reflexão ampla e aprofundada sobre o projeto escolar; o diagnóstico das condições estruturais e conjunturais da escola e do seu contexto; e operacionalizar os fins e objetivos estabelecidos em seu projeto político pedagógico e que a escola se propõe alcançar por meio das ações planejadas.

A seguir, apresentamos o relato parcial da pesquisa qualitativa, de tipo etnográfico, realizada na escola e que se utilizou da observação, da entrevista e da análise documental como instrumentos de coleta de dados.

\section{O EMPÍRICO: COMO A ESCOLA REALIZA SEU PLANEJAMENTO}

O calendário escolar contempla um período reservado à elaboração do Plano Escolar. É uma exigência do Regimento Comum ${ }^{3}$ e antecede o início das aulas. Na EEPSG "Gabriel Arcadas", o período destinado a essa tarefa foi fixado nos quatro dias que antecederam o início das aulas.

Para dar início ao planejamento a diretoria convocou uma reunião geral com a presença obrigatória de todos os professores, isto é, de todos aos quais já haviam sido atribuídas classes ou aulas, porque existiam aulas de algumas disciplinas para as quais não havia professores contratados. Estes só seriam conhecidos em etapa ainda a ocorrer. Essa reunião foi marcada para o período da noite do primeiro dia de planejamento.

A primeira parte da reunião foi dedicada a comunicações gerais da diretoria e recomendações sobre procedimentos a serem adotados pelos professores em relação ao funcionamento da escola. Deu-se destaque ao calendário escolar, agora com duzentos dias letivos; aos avisos sobre cumprimento de horários e das normas estabelecidas sobre conduta dos alunos. Para reforçar seus apelos sobre o assunto ameaçou a diretora: "Gente, é muito desagradável eu ter que chamar a atenção e desautorizar um professor”.

Sobre o planejamento, propriamente dito, foram apresentados alguns elementos para orientar os trabalhos dos professores. Por meio de um quadro foram apresentados os resultados do aproveitamento escolar dos alunos no ano passado, comparados com os mesmos resultados do ano anterior. Mesmo que no geral os índices de aprovação, retenção, e evasão tenham se mostrado favoráveis, em alguns casos foram observados aumentos nas médias de retenção. Segundo a análise da diretora os números não traduzem a realidade já que em sua opinião

3 O Regimento Comum é o regimento único outorgado pelo Estado de São Paulo a todas as unidades escolares da sua rede de ensino. 
a escola melhorou muito. Após o que completou: "Esses aumentos, eu acho, ocorreram porque nós trabalhamos mais seriamente. Vocês não acham, também, gente?" No que foi seguida em uníssono pelos professores: “Ah, nós achamos!” Transcritos do Plano Diretor de ano anterior estavam no quadro negro os itens para repensar a escola e o processo pedagógico: a) Prioridades da escola; b) Diretrizes; c) Objetivos Gerais; d) Objetivos Específicos. Sobre eles se manifestou a diretora: "Eles poderão ser modificados; entretanto, acho que eles deverão ser mantidos porque são básicos e traduzem objetivos que são permanentes na escola." Resultado: os itens foram mantidos sem discussão.

Vários outros tópicos foram abordados pela diretora, especialmente os relativos a utilização dos recursos didáticos da escola. Para ela, os professores deveriam empenhar-se para conhecer os recursos que a escola possui para melhor utilizá-los. Há, entretanto, que se ter organização para evitar solicitações feitas "em cima da hora" como geralmente ocorre, segundo a diretora, com a maioria dos professores que solicitam, e completa: "O 'Gabriel'4 não tem tudo, mas tem o suficiente para atender ao que é básico e essencial. Não adianta, entretanto, a escola ter material. É preciso gente para fazer."

O tom da fala da diretora é, em geral, de elogio à qualidade dos professores e ao trabalho da escola. Mas faz, também, ressalvas pontuais ao trabalho dos professores e às condições existentes para a execução do Plano Diretor. Reconheceu que, no ano anterior, os recursos referentes a alguns projetos da escola só foram liberados já ao final do ano, com prejuízo para o planejado.

Ao término dessa parte, e de passagem, abordou de forma um tanto confusa o tema da escolha dos coordenadores de áreas sugerindo, nas entrelinhas, que se não houvesse manifestação contrária permaneceriam os mesmos do ano anterior. Como não houve qualquer manifestação...

$\mathrm{Na}$ sequência os professores foram divididos em cinco grupos com a incumbência de sugerirem temas dos quais um seria escolhido como integrador para o trabalho de toda a escola - do Ciclo Básico (CB) ao $3^{\circ}$ colegial.

Reunidos novamente, em painel, os grupos apresentaram suas sugestões. Os temas sugeridos e a respectiva frequência com que apareceram foram: Preconceito (4); Violência (1); Postura Inovadora (1); Aluno: Realidade e Fantasia (1); Estudo da realidade do bairro (1); Vida (1). Após suas apresentações, por votação foi escolhido o tema Vida que recebeu 53 votos contra 22 para o tema Preconceito, o segundo mais votado.

Digno de registro, nessa etapa, foi a presença do tema Preconceito como

\footnotetext{
4 A maioria dos agentes da escola ao se referir à EEPSG “Gabriel Arcadas" o faz através do prenome do patrono da escola. Assim, em muitas passagens deste estudo, que correspondem a falas dos agentes, a escola será referida como "o Gabriel”.
}

202 - RBPAE - v. 32, n. 1, p. 193 - 210 jan./abr. 2016 
sugestão de quatro dos cinco grupos, que acabou sendo derrotado pelo tema Vida, que apareceu uma só vez e, ainda assim, dentre os três temas apresentados por um mesmo grupo. As defesas feitas para cada tema pelos grupos proponentes foram fracas numa demonstração sintomática de que aquela atividade, aparentemente valorizada pela direção, não encontrou ressonância no corpo docente e foi tratada de forma burocrática. O resultado da votação de certa forma corrobora essa inferência.

O segundo dia de planejamento, ainda como atividade conjunta de todos os professores, foi reservado à realização de uma palestra feita por um professor convidado. O palestrante, coordenador pedagógico de escola particular, fez um relato da experiência realizada na escola onde trabalha com vistas à integração das disciplinas do currículo, de modo a facilitar uma abordagem interdisciplinar dos conteúdos escolares.

A atividade teria sido relevante se realizada como parte de uma discussão mais aprofundada sobre o tema ou se a questão da interdisciplinaridade fosse uma preocupação que perpassasse a maioria do corpo docente. Aparentemente nenhuma das duas coisas estava presente e a atividade, sem articulação com o processo de planejamento, perdeu-se enquanto contribuição para a reflexão coletiva. Um indicador da falta de interesse sobre o tema foi a ausência de referência a ele nas reuniões que se seguiram. Foi uma atividade que não deixou qualquer semente de discussão, que somente serviu enquanto durou, ou seja, estava deslocada na programação do planejamento.

No terceiro dia de planejamento, quando então se daria início à elaboração dos planos de ensino das disciplinas, os professores foram convocados a participar de reuniões em seus respectivos turnos de trabalho. Os professores do diurno (manhã e tarde) dedicaram a reunião quase que exclusivamente a sugerir subtemas que iriam orientar o planejamento das áreas a partir do tema integrador já escolhido. Face à natureza ampla do tema Vida foram sugeridos onze subtemas que guardavam pouca ou nenhuma articulação entre si e continuavam igualmente amplos para orientar a elaboração dos planos de ensino.

$\mathrm{Na}$ reunião do período noturno, dirigida pela coordenadora daquele período, já que após o primeiro dia as reuniões se realizaram sem a presença da diretora, apresentou-se inicialmente, já escrita no quadro negro, a relação dos subtemas escolhidos pelos professores do período diurno que foram anunciados como aqueles que deveriam ser levados em consideração pelos professores do noturno, pois isso significaria ganho de tempo e simplificação da tarefa dos mesmos.

Diante desse andamento proposto, um professor, tomando a palavra, questionou a maneira como estava sendo conduzido o planejamento, 
especialmente o fato de as reuniões estarem se realizando em períodos diferentes para o cumprimento de tarefas que eram comuns a todos os professores posto que há séries escolares que se repetem em dois ou mais períodos. Tomando como exemplo o assunto em pauta naquela reunião, argumentou que os professores do diurno haviam discutido, estabelecido metas e escolhido subtemas e que aos do noturno restou conhecerem e acatarem os resultados sem poder discuti-los, ou seja, adotando-os sem nenhuma reflexão.

Em apoio ao colega, manifestou-se uma professora, acrescentando que o planejamento é sempre feito com pouco tempo, o que impede uma reflexão coletiva dos professores. A título de reforço do seu argumento relatou o exemplo de outra escola pública estadual, onde seu marido leciona, na qual as aulas já estavam em andamento sem que se tivesse realizado qualquer planejamento prévio.

A coordenadora da reunião concordou com as críticas e informou que o processo é estabelecido pela CENP e que aquela parece "não querer que se planeje". Informou, então, aos professores que ela havia proposto outra organização de reuniões para o planejamento e que não obteve sucesso porque a direção da escola estava preocupada em atender ao prazo estabelecido pela Delegacia de Ensino, posto que o não cumprimento daquele poderia prejudicar a escola, especialmente no recebimento de verbas.

Diante disso, estabeleceu-se um acalorado e tumultuado debate, que exigiu, após algum tempo, a presença da diretora. Solicitados a expor suas críticas à diretora observou-se uma solene "afinada" geral, ou seja, houve um recuo constrangedor das posições até então assumidas e veementemente defendidas pelos professores. Diante da diretora, as críticas se abrandaram e perderam sua força enquanto reivindicação dos professores na luta pela conquista de espaço e de condições para realizar seu trabalho a partir de um processo de reflexão coletiva, condição minimamente essencial para a construção de um projeto pedagógico escolar.

Esvaziado o episódio, que poderia ter-se transformado em ganho na luta pela valorização da dimensão pedagógica da escola, diante das imposições burocráticas, a questão foi encerrada com as explicações da diretoria sobre a importância de se cumprirem os prazos estabelecidos pela Delegacia de Ensino, e mais, sobre o fato de que aquelas limitações não eram tão graves pois "não se pode pretender um plano perfeito", que se poderia aperfeiçoá-lo ao longo do ano e, finalmente, que as conclusões feitas pelos professores do diurno não eram fechadas.

Em prosseguimento, sem que se discutissem as conclusões e subtemas propostos pelos professores do diurno, passou-se à tentativa de operacionalização 
do desenvolvimento dos subtemas pelas disciplinas do currículo. Várias sugestões foram sendo apresentadas, discutidas e, em seguida, abandonadas. A reunião terminou sem conclusões.

No último dia do período de planejamento ocorreram reuniões nos três períodos. Pela manhã reuniram-se os professores de $\mathrm{CB}$ à $4^{\mathrm{a}}$ série do primeiro grau, sob a direção da coordenadora dessas séries.

Inicialmente, procedeu-se à distribuição dos diários de classe, sobre o qual foi solicitado capricho no preenchimento, e das chaves das salas para que as professoras tirassem cópias, já que cada uma seria responsável por sua sala.

Em seguida, foram dados avisos e feitas recomendações gerais sobre o funcionamento da escola. Alguns foram repetições daqueles já feitos pela diretora na reunião geral do primeiro dia de planejamento. Dentre os que se dirigiam especificamente ao grupo estavam o da necessidade de cumprimento do horário das reuniões. Sobre o assunto, assim se manifestou a coordenadora: "Nas reuniões de HTP quem chegar atrasado ou sair mais cedo ficará com falta; as comadres não poderão sentar perto; não será permitido passar receita, nem pedir licença para ir ao banheiro e não voltar mais".

Em tom de apelo, a coordenadora recomendou que todos contribuíssem para a construção de um clima harmonioso, fraternal e familiar. Que se evitassem as fofocas e críticas às colegas e serventes. Que se evitassem, também, as conversas de corredor durante o horário de aulas, e finalizou dizendo: "Gente, quando bater o sinal, se estiver experimentando alguma coisa para comprar, larga na hora. Nada daquela conversa de mais um pouquinho que eu já vou", referindo-se aí aos intervalos diários entre as aulas.

Sobre a ocorrência de problemas disciplinares, recomendou a coordenadora que os professores os resolvessem sem encaminhar os alunos para a diretoria. "Afinal, vocês são profissionais", finalizou.

Justificando a grande quantidade de avisos e recomendações assim se expressou a coordenadora: "A escola é como uma grande empresa; para funcionar é preciso ter normas e serem cumpridas".

Interrompendo a reunião a diretora solicitou um tempo para orientar as professoras sobre o uso de camiseta pelos alunos, a título de uniforme. Informou que as professoras deveriam intermediar a venda das camisetas aos alunos. Ao fornecer o preço das camisetas informou que eles seriam atualizados segundo a variação do dólar. Informou, também, que a escola iria distribuir duas mil e quinhentas calças aos alunos, recebidas do Governo do Estado, e que, para isso, elas deveriam anotar a numeração usada pelos seus alunos. Encerrou recomendando: "Gente, cuidado para não espalhar na comunidade a notícia de que a escola estará distribuindo calças. Porque senão haverá uma correria à escola”. 
A condução da reunião foi caótica e correu num clima descontraído. A coordenadora falou o tempo todo em alto volume de voz para superar o ruído das conversas paralelas que foram permanentes, apesar dos constantes apelos da coordenadora. Não houve sequência dos assuntos tratados. A cada aviso uma conversa geral seguida de um respectivo: "Gente, posso continuar...", o que nem sempre foi possível. Diante do caos, algumas vezes, a coordenadora mudou seu tom falando "duro". Aparentemente ninguém se importou. Porque virou hábito, pela repetição, e porque todos sabem que as recomendações e as "broncas" são coisa normal e quase obrigatória da parte dos "superiores", no desempenho do seu papel. Funcionou, na reunião observada, como um jogo que não é "pra valer". Assim sendo, a reunião terminou em clima descontraído.

A reunião no período da tarde ocorreu de maneira segmentada. Professores de $\mathrm{CB}$ à $4^{\mathrm{a}}$ série tiveram uma reunião com pauta idêntica à do período da manhã. Os demais trabalharam em pequenos grupos na elaboração dos planos de ensino.

A reunião do período noturno, com frequência significativamente menor do que nos dias anteriores, ocorreu com os professores divididos em grupos, por disciplinas ou áreas, para a elaboração dos planos das disciplinas. Em nenhum caso os professores concluíram suas tarefas de elaboração do plano de ensino. A partir daí, essa tarefa passou a ser responsabilidade individual de cada professor.

\section{DISCUSSÃO}

A descrição das atividades iniciais do ano, com ênfase na dinâmica das reuniões de planejamento escolar, apresenta um rico quadro sobre como a escola se prepara para realizar sua tarefa anual de execução do currículo; sobre qual a importância atribuída ao planejamento; qual a participação dos professores na construção do projeto escolar; e, especialmente, face ao interesse deste estudo, como se dá nesse processo a atuação da administração da unidade escolar, vista aqui como a atuação dos agentes que compõem a direção da escola.

A leitura do relato acima por aqueles que já tiveram a oportunidade de participar profissionalmente dessas atividades, hoje comuns e obrigatórias nas escolas públicas estaduais, certamente conduzirá à identificação de muitos elementos comuns entre sua experiência e o contido no relato. Ou seja, há certo padrão na forma como as escolas públicas estaduais conduzem todo o processo escolar. No caso específico do planejamento, a visão predominante é de tal forma burocrática que se poderia dizer que aquele que algum dia participou de um planejamento na escola pública não necessita participar de qualquer outro. 
Tal afirmação extremada parecerá imprópria para um estudo acadêmico, mas é ela que sucintamente traduz aquilo que, nesse aspecto, transformou-se o planejamento escolar. O planejamento na escola pública não é um instrumento metodológico de trabalho. Sua realização tem por fim a produção de um documento, o plano escolar, que será utilizado para atender a uma exigência burocrática. Essa perspectiva, que é predominante na prática escolar, é responsável pela perda da visão do planejamento como parte do processo de construção coletiva do projeto pedagógico; momento de reflexão sobre as funções sociais da educação, sobre o papel da escola, sobre o trabalho docente, sobre o conhecimento, sobre as condições concretas da escola para a realização de seu mister, sobre a racionalidade interna da escola, enfim, sobre todos os elementos que direta ou indiretamente determinam a racionalidade social da escola.

O relato serve também para revelar a maneira amadorística como são tratados e conduzidos os processos de trabalho na escola, decorrente da falta de compromisso político e de competência técnica, ou seja, daquelas condições apontadas como cruciais e complementares para que os professores sejam verdadeiramente educadores.

Não se trata, como veremos adiante, de atribuir culpa aos educadores escolares no sentido individual. Tanto a falta de compromisso quanto de competência, que se observa na escola pública são engendradas pelas políticas do Estado para a educação. A depreciação da educação se manifesta em primeiro lugar pelos aviltantes salários oferecidos aos educadores; em segundo, pelas precárias condições de trabalho. Estas duas ordens de fatores, dentre outras, estão na raiz das deficiências apresentadas pela escola pública.

Algumas passagens do relato merecem destaque pela ilustração que oferecem às críticas aqui desenvolvidas sobre o processo de trabalho na escola. A reincidência, em várias reuniões, de temas voltados ao cumprimento de normas que visam ao regular funcionamento da escola e ao controle disciplinar dos alunos revela a importância atribuída pela direção da escola às questões de manutenção da ordem e do cumprimento dos prazos estabelecidos pela burocracia para as tarefas solicitadas. Esses, parece, são os principais fatores levados em conta na avaliação funcional dos diretores pelos órgãos superiores da burocracia estatal.

Significativo e exemplar, para ilustrar as relações de poder na escola e, ao mesmo tempo, a predominância da visão burocrática foi o episódio relatado das críticas feitas por professores ao processo de planejamento. A intervenção da diretora foi suficiente para inibir uma justa reivindicação por maior participação dos professores no planejamento. Ao mesmo tempo, suas razões em defesa do atendimento do prazo estabelecido pela Delegacia de Ensino foram aceitas sem contestação, por todos os professores, como suficientes para justificar o 
apressamento na confecção do Plano Escolar, mesmo com as imperfeições daí decorrentes e conhecidas. A alegação da diretora de que o plano escolar poderia ser melhorado ao longo do ano não encontra fundamento nas condições de funcionamento da escola que não prevê espaços institucionalizados para esse processo de reflexão coletiva sobre o projeto pedagógico da escola.

Outra questão que exige reflexão é a da participação da direção no processo de planejamento escolar. O relato, resultante de observação, registrou a ausência da diretora e assistentes de direção na maior parte das atividades de planejamento. A participação da diretora limitou-se a aparições esporádicas para fornecer informações ou esclarecer dúvidas. Essa constatação parece reforçar os argumentos da predominância da concepção burocrática na administração da escola pública, ou seja, a direção tem função de controle, que ela exerce por meio de mecanismos burocráticos, descolada das atividades-fim da escola, portanto, das questões pedagógicas.

De maneira geral, os temas foram tratados, nas reuniões de planejamento, de forma abreviada, conduzindo a conclusões e decisões apressadas e apriorísticas. Não há um processo de discussão e reflexão que permita o amadurecimento e avanço da práxis individual e coletiva dos educadores, o que justifica, em parte, serem esses planejamentos repetições dos realizados no passado, ou seja, a cada novo período escolar os problemas com que se defronta a escola são os mesmos dos períodos anteriores e recebem o mesmo tratamento já consagrado pelo senso comum, que orienta a práxis dos agentes escolares. Em resumo, observa-se que na escola pública parece não haver acúmulo de conhecimento sobre as práticas escolares; as experiências anteriormente vividas não são levadas em conta para orientar as ações futuras. Poder-se-ia dizer, recorrendo a Sánchez Vázquez (1977), com fundamento nesse indicador, que a práxis dos agentes escolares é reiterativa e espontânea.

Romeu (1987), através de estudo exploratório, faz um cotejamento entre objetivos e metas formalmente estabelecidos pelas escolas públicas estaduais e aquilo que efetivamente realizam na prática. $\mathrm{O}$ estudo teve como amostra dez escolas jurisdicionadas a uma Delegacia de Ensino da região do Vale do Paraíba, no Estado de São Paulo. O ponto de partida para a análise das propostas foram os Planos Escolares elaborados pelas escolas. Segundo a autora, "O confronto entre os dados obtidos na análise do Plano Escolar e das entrevistas permitiu uma maior aproximação da realidade das escolas. Possibilitou, assim, inferir a existência ou não de uma proposta de trabalho, o grau de envolvimento, principalmente dos professores, nessa proposta, e os fatores que facilitam ou dificultam a formulação de um plano comum de ação" (Romeu, 1987, p. 59). 
A análise dos Planos Escolares revelou, segundo a autora, que, em sua elaboração, predominou o formalismo desprovido de qualquer preocupação com a formulação do projeto escolar. " $\mathrm{Na}$ totalidade dos casos considerados, nos últimos três anos, os planos são transcritos de um ano para outro, sem nenhuma alteração."(Idem, p. 61)

Os resultados da pesquisa realizada por Romeu (1987) ilustram, e de certa forma confirmam, os dados obtidos no nosso estudo de caso sobre o processo de planejamento e sua relação com a formulação do projeto escolar. Suas conclusões, em muitos aspectos, se aplicam aos nossos dados evidenciando que há determinações gerais e institucionais que se aplicam às escolas da rede estadual que resultam em padrões razoavelmente semelhantes de comportamento organizacional em todo o universo das suas unidades escolares.

Daí parece lícito supor que nossos dados poderão, em grande parte, ser estendidos para outras unidades na medida em que revelem ser determinados por condições estruturais da rede escolar, muito mais do que por condições conjunturais da unidade escolar pesquisada.

\section{CONCLUSÃO}

Quando, no discurso acadêmico, enfatiza-se a indispensável democratização da escola, e de sua gestão para que a educação alcance suas finalidades pedagógicas e sociais, é preciso refletir o significado que essa assertiva tem no âmbito da realidade escolar. Parece haver, sobre a democratização da escola, um consenso entre as vertentes pedagógicas dominantes; entretanto, a prática escolar revela que ali predomina o imaginário dos agentes, isto é, a dimensão subjetiva, sobre a dimensão objetiva.

Assim, quando se analisa a prática escolar a partir dos referenciais teóricos, ou pelo menos do discurso pedagógico progressista, constata-se o enorme abismo entre eles. Cabe aí, então, perguntar: o que é isso do que se fala como algo simples e imediato, para não dizer óbvio, sobre gestão democrática e que, entretanto, parece estar tão distante da escola? Parece mesmo que o discurso acadêmico se refere a uma realidade diferente da escola real e com ela incompatível; que o que se propõe é inaplicável, ou até mesmo conflitante, com aquela realidade.

Durante a realização da pesquisa de campo deste estudo, que teve a duração de um ano, em nenhuma oportunidade dentre as muitas observações de reuniões de professores, de Conselho de Escola, de Associação de Pais e Mestres etc., discutiu-se ou se mencionou qualquer aspecto da democratização da escola e de sua gestão. Democratização da escola parece ser uma expressão não 
incorporada ao vocabulário escolar, permanecendo apenas como preocupação e temática acadêmica.

Finalmente, como se constatou nas discussões, o planejamento escolar tem se constituído em procedimento burocrático, esvaziado, portanto, dos sentidos que poderia assumir na escola, principalmente o de ser o elemento catalisador da reflexão coletiva sobre temáticas que contribuiriam para a construção do projeto político-pedagógico da escola. Em reforço a essa conclusão, pode-se constatar que naquelas redes escolares públicas, estaduais ou municipais, que passaram a adotar um currículo único, apoiado com material pedagógico padronizado, ficaram reduzidos a importância do projeto político-pedagógico e o planejamento.

\section{REFERÊNCIAS}

PARO, Vitor H. Administração escolar: introdução crítica. São Paulo: Cortez: Autores Associados, 1986.

ROMEU, Sonia A. Escola: objetivos organizacionais e objetivos educacionais. São Paulo: EPU, 1987.

RUSSO, Miguel H. Teoria e prática da administração escolar: confluências e divergências. 1995. (311p.) Tese (Doutorado em Educação) - Universidade de São Paulo, 1995.

Apontamentos sobre o planejamento escolar. São Paulo: Centro Estadual de Educação Tecnológica Paula Souza, 1991 (documento de trabalho, mimeo.).

SÁNCHEZ VÁZQUEZ, Adolfo. Filosofia da práxis. 2a ed. Rio de Janeiro: Paz e Terra, 1977.

MIGUEL HENRIQUE RUSSO é professor-pesquisador do Centro de Estudo, Pesquisa e Desenvolvimento em Educação - CEPEDE. Doutor em Educação pela Universidade São Paulo - USP e Mestre em Educação (Administração e Supervisão Educacional) pela Universidade de Campinas - UNICAMP. E-mail: mh.russo@uol.com.br 